\title{
Using Analytical Hierarchy Process For Finding Suitable Sites for Solar Power Plants
}

\author{
Neda Nouri, Amin Basiri, Anahid Basiri
}

\begin{abstract}
- the demand for the renewable energy sources is very high and this is mainly due to the fact that fossil fuels are finishing and they may not be environmental friendly. While it is highly important that the remaining amount of non-renewable energy resources are preserved for the future generations, other resources of energy can become more and more important. This is in particular very important for the developing countries such as Iran, which most of its export income is on the basis of selling oil, despite the huge potential of using renewable resources such as wind and solar; The amount of solar energy reception and average annual sunny hours (i.e. over 2900 hours), Iran is considered as one of the suitable countries in terms of capability for creating solar power plants. In the present paper, it has been attempted to recognize the appropriate locations to take advantage of this energy. In this regard, at first, the influencing factors on the solar energy are investigated, and then, using FAHP decisionmaking techniques the most suitable locations in Iran for the construction of solar power plants are introduced. According to the performed investigations, the most important factors that should be considered include: sunny hours, ambient temperature, height, and the amount of dust.
\end{abstract}

Keywords-Solar Energy, Analytic Hierarchy Process, Hybrid Fuzzy-AHP Algorithm.

Islamic Azad University, Iran

Islamic Azad University, Iran

The University of Southampton, UK

\section{Introduction}

The sun is a shining giant ball in the center of the solar system and supplier of lighting, heating and other energies for the Earth. Almost all of energy resources on the earth are provided by the sun. Only nuclear energy, the earth's interior energy, and the part of tidal energy that is generated by the moon's gravity, are not produced by the sun. Based on the scientific estimations, it is about
4.5 billion years passing the birth of this fiery ball, and it could still be considered as an enormous source of energy up to the next 5 milliard years. Nearly, it is $1.1 \times 1020 \mathrm{kWh}$ energy emitted from the sun in each second. Only one-two billionth $\left(1 / 2 \times 10^{9}\right)$ of this

energy is intercepted by the outer surface of the Earth's atmosphere. This energy is equivalent to $5.1 \times 1018 \mathrm{kWh}$ per year. Because of reflection, diffraction and absorption by gases and suspended particles in the atmosphere, only $47 \%$ of this energy arrives the Earth's surface. Therefore, the energy radiated on the Earth's surface is about $7 \times 1017 \mathrm{kWh}$, annually. Photovoltaic (PV) systems are used for public and agriculture consumptions, as power plants independent of global network or systems connected to the global network with fixed or movable structure, or in small units with low power to provide electrical energy needed for small calculators to large power plant systems.

\section{Solar Radiation Potential and The Radiation Map in Iran}

Solar energy is one of the resources for renewable energies and is the most important of them. The amount of solar energy radiation is variable in different parts of the world and the highest is in the Sunbelt. Iran is country that is also located in high radiation areas and studies show that the use of solar equipment is suitable in Iran, so that it could provide a part of energy requirements for the country. According to the specialists, having 300 sunny days in more than twothirds of the country and the average radiation equal to $4.5-5.5 \mathrm{kWh} / \mathrm{m} 2$ per day, Iran is specified as a country with high potential in terms of solar energy. Some solar energy experts have taken a step further and ideally claim that if Iran equips its desert area with reception systems for the radiant energy, it could provide the energy requirement for wide parts of the region and could be activated in exporting electrical energy. Based on the studies performed by German Aerospace Center (DLR), in an area more than $2000 \mathrm{Km} 2$, there is the possibility of installing more than $60,000 \mathrm{MW}$ of solar thermal power plants. If we allocate an area equal to $100 \times 100 \mathrm{Km} 2$ to build a photovoltaic solar power plant, 
the generated electricity will be equivalent to the total production of electricity in 2010.

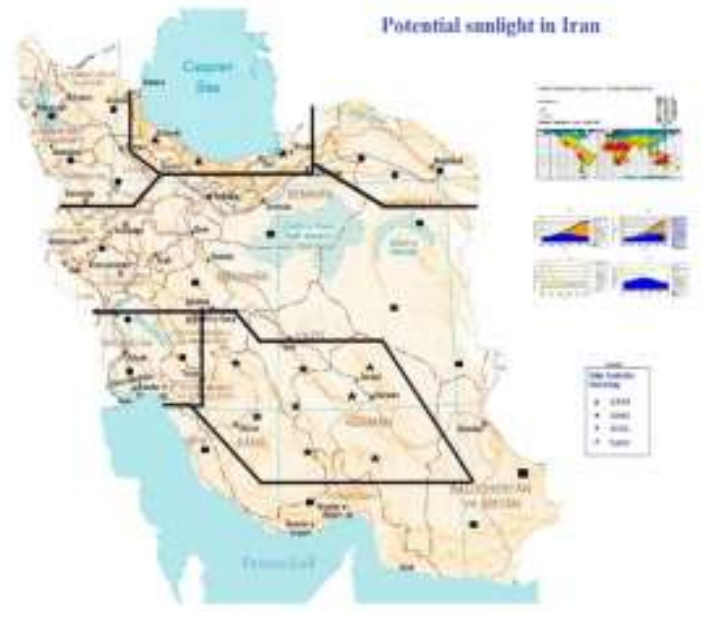

Figure 1. Potential of sunlight in different regions of Iran

\section{The Proposed Methodology based on Analytic Hierarchy Process (AHP)}

The AHP model procedure starts with specifying elements, making decisions, and prioritizing them. These elements are including different ways of working and prioritizing the features.

\section{A. Creating A Hierarchical Structure}

Transforming the investigated subject or issue to the hierarchical structure is considered as the most important part of analytic hierarchy process. In the case of locating renewable power plants, the purpose is to select an appropriate location for the renewable power plants among several options. The criteria and sub-criteria are including factors that make a difference in the options. The validity of each location is measured based on the criteria. In AHP method, each criterion has a special weight, which should be applied by the user in different ways. It also could be possible to divide each criterion into several smaller fragments, compare them with each other, and weighting them.

\section{B. Determining Importance Coefficients Of Criteria And Sub-Criteria}

There are several methods to determine the importance coefficient of criteria and sub-criteria, which the most common is binary comparison. In this method, the criteria are compared and the degree of importance for each criterion will be determined relative to the other one. For this purpose, a standard procedure provided by Saati can be used. The procedure is so that a number between 1 to 9 is attributed to each binary comparison.
After determining the importance coefficients of criteria and sub-criteria, the importance coefficient of options should be determined. In this step, the priority of each of the options is judged related to each of the sub-criteria, and if a criterion does not have sub-criterion, it will be judged with its own criteria, directly.

TABLE 1. Degree of importance based on AHP

\begin{tabular}{ll}
\hline \multicolumn{2}{l}{ The fundamental scale of absolute numbers } \\
\hline Preferences & Numerical Value \\
\hline Equally preference & 1 \\
\hline Moderately preference & 3 \\
\hline Strongly preference & 5 \\
\hline Very strongly preference & 7 \\
\hline Extremely preference & 9 \\
\hline
\end{tabular}

The process of obtaining weights of the options relative to each of the criterion is similar to the determination of importance coefficient of the criteria relative to the purpose. The comparison of various options is performed relative to sub-criteria or criteria, while the comparison of criteria with each other is performed relative to the purpose of the investigation. The sub-criteria are qualitative as well as they are quantitative. This indicates the other advantage of analytical hierarchy process, which is involved with a combination of qualitative and quantitative criteria.

\section{c. Fuzzy- Analytical Hierarchy Process (Fuzzy-AHP) Algorithm}

Despite the general popularity, due to its inability in combining inherent ambiguity and the imprecision associated with the mapping of the perceptions of decision-makers with accurate numbers, AHP is criticized (Deng, 1999). The fuzzy logic that was introduced against classical logic, is considered as a powerful tool for the solution of problems associated with complex systems, in which the problem or issues dependent to ratiocination is making decisions and human perception (Kurepazan, 2008). Actual phenomena are not only black or only white, but somewhat are gray. Actual phenomena are always fuzzy, vague and imprecise (Azar and Faraji, 2008). The range of classic membership functions ((X) xA) is the twomember set of zero or one, while, the range of fuzzy membership functions $(\mu \tilde{A}(x))$, is a closed range of zero and one (Kurepazan, 2008). The theory of fuzzy sets is a mathematical theory designed for modeling the vague of processes dependent on human knowledge (Lin et al., 2007). The decision-maker can freely choose the domain of desired values. Fuzzy number can express 
uncertain judgment of the expert (Vahidnia et al., 2009). Hence, FAHP operates a domain of values for expressing the uncertainty of decision-makers (Lee et al., 2008). In this method, fuzzy numbers are used for pairwise comparison of the options and geometric mean method is used for obtaining weights and superiorities, because this method is simply generalizable to fuzzy state and also determines a unique answer for pairwise comparison matrix. In this method, the decision-maker can express the pairwise comparison of the elements of each level in the form of trapezoidal fuzzy numbers. In order to prepare the pairwise comparison matrix, the viewpoints of experts in the natural resources and geology were used. The weighting and the calculation of fuzzy numbers were performed in Excel, and the combination of layers and locative analyses were done in the ArcGIS software. The work algorithm could be expressed in three steps. For this work, Buckley method was used in the first and second steps, and Unison method has been used in the third step. Step one: In this step, the decision-maker specifies the pairwise comparison matrices. The elements of these matrixes will be trapezoidal fuzzy numbers. The superiority of ith element on $j$-th element and also the superiority of $j$-th element on the i-th element will be as follows:

$$
\begin{aligned}
& a=(a i j, b i j, c i j, d i j)(1) \\
& \left.a i j=\frac{1}{d i j}, \frac{1}{c i j}, \frac{1}{b i j}, \frac{1}{a i j}\right)(2)
\end{aligned}
$$

Step two: In this step, by the use of geometric mean method, the weight of each features rij(at) of sub-layers is separately calculated and the weight (or the superiority) of each criterion (the layers) is also calculated. The procedure steps is as follows, similarly, bi and ci, b, c, di, and d could be defined. Therefore, the fuzzy weight of the feature and criteria could be obtained from the following equations:

$$
\begin{aligned}
& a=\sum_{i=1}^{3} a_{j}(4) \\
& \bar{w}_{j}=\left(\frac{a_{1}}{d}, \frac{b_{i}}{c}, \frac{c_{j}}{b}, \frac{d_{i}}{a}\right)(6)
\end{aligned}
$$

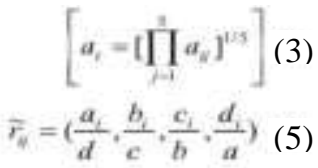

\section{Locating solar power plant}

Sunny hours is the most important continental parameter, which is the indicator of the amount of received energy from the Sun. The sunny hours is the total monthly or annually hours of a region. Dust: From the atmospheric important compounds especially around the Earth's surface, are the non-gas and solid combinations that are so called aerosol. The aerosols absorb $51 \%$ of short-wave solar energy, thus, the locations that have the minimum days of dust pollution in the year, are of importance. Height: The less altitude a region has, the further thickness of the atmosphere will be there. A thicker atmosphere implies on a higher concentration of components and absorption or reflection factors. Since the coarser and more concentrated materials are gathered in the lower levels, the atmosphere above mountains is less dense and its thickness is also less. In addition to the entrance of short wave solar energy, the atmosphere thickness and its components control the long-wave energy of the Earth. Hence, because of the high energy-reception, highlands are more susceptible than lowlands. The region's temperature: One of the components of photovoltaic systems is the energy converter that is solar panels. In order that this system provides required power and energy for the desired load, it must be deigned properly. One of the factors that is influencing in determination of the size of required panel, is its efficiency. The panel efficiency depends on its temperature and the panel temperature is also caused by the ambient temperature and the solar radiation intensity. As it was noted, the panel output power is changed with variations of cell temperature. According to the equations in Zack's book, the output power of panel has an inverse relationship with temperature.

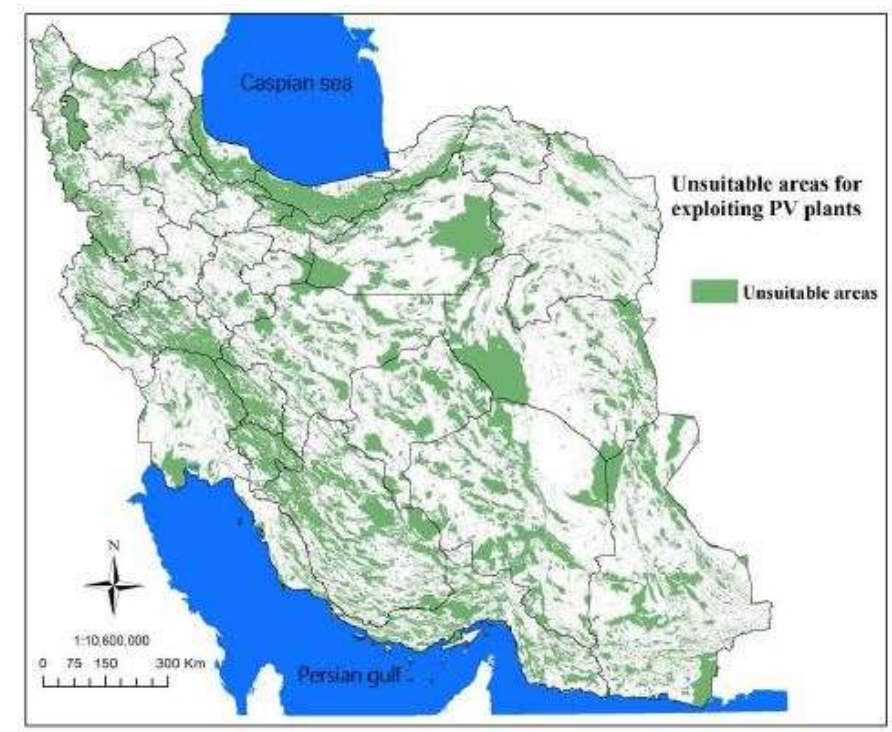

Figure 2. Final map of unsuitable areas.

\section{Results and Discussion}

The obtained results indicated that the combination of FAHP, SAW with GIS has a high accuracy in land suitability analysis modeling and, in this way, climatic criteria have the most relative importance. The results revealed that $14.7 \%, 17.2 \%, 19.2 \%, 11.3 \%$ and $1.8 \%$ of Iran's area are positioned as excellent, good, fair, low and poor classes, respectively. About $35.8 \%$ of the areas 
in Iran are in the restricted area (Figure 2). Based on this, we can say that this is due to the high slope or elevation. As mentioned earlier, the regions with slope greater than $11 \%$ as well as above $2200 \mathrm{~m}$ from sea level are unsuitable for the construction of PV farms. Hence, the regions with restricted areas that are not suitable for creating large farms may have a better situation for implementation of small off-grid solar technology. Table 2 shows the results for Iran's provinces based on the percentage of area related to each defined class. As indicated in Table 2, Golestan, Ardabil, North Khorasan, Gilan and Mazandaran provinces have the highest area in the poor class due to the rain forest areas in the northern part of Iran. Moreover, as the suitable provinces, Kerman, Yazd, Fars, Sisitan and Baluchestan, Southern Khorasan and Isfahan, with half the total area of Iran, are included in the regions with the most excellent suitability for exploiting solar energy. Area classification of the most suitable provinces based on the percentage of area related to each class including excellent, good, fair, low and poor, as well as unsuitable area is presented in Figure 3.

Table 2. The percentage of area related to various classes at the provincial level.

\begin{tabular}{|c|c|c|c|c|c|c|}
\hline Proviner & $\operatorname{por}\left(y_{0}\right)$ & $\operatorname{Lar}(\%)$ & $\operatorname{Fari}\left(Y_{0}\right)$ & $\operatorname{Covol}(\%)$ & Excellent(c) & Unsuitable (y) \\
\hline Kerman & 0 & 1.6 & 9.9 & 19.2 & 39.5 & 31.2 \\
\hline Yaad & 0 & 1.1 & 9 & 24.3 & 30.1 & 35.8 \\
\hline Khorasan & 0 & 5.5 & 15.1 & 2.1 & 25.2 & 34.2 \\
\hline Sistan and Baluchestan & 0 & 3.6 & 21 & $B 3.3$ & 19.9 & 30.9 \\
\hline Ifstang & 0 & 5.2 & 12.2 & 25.1 & 18.1 & 34.2 \\
\hline
\end{tabular}

Due to the geographical location and climatic conditions of central and southern regions of Iran such as aridity, high quantity of sunny days and good situation for other defined criteria in this research, Kerman, Yazd, , Sisitan and Baluchestan, Khorasan and Isfahan will be attractive for investment in solar energy projects. Figure 4 presents a closer view of the geographical location and classification in these provinces. Due to obtained data in this research, we can also determine the prioritization in country.

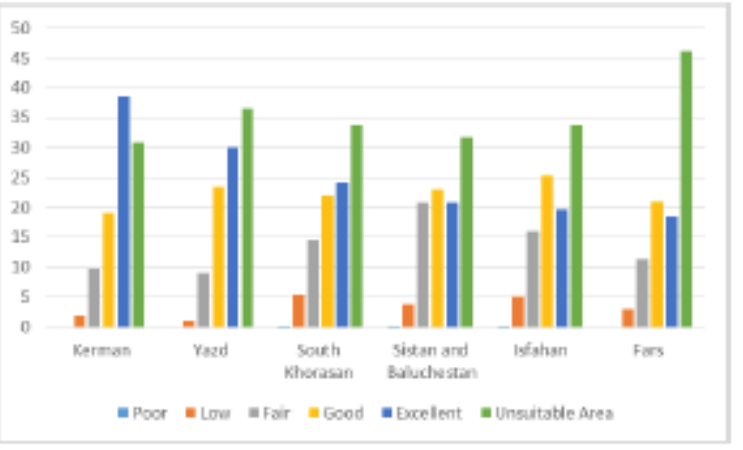

Figure 3. Area classification of the most suitable provinces.

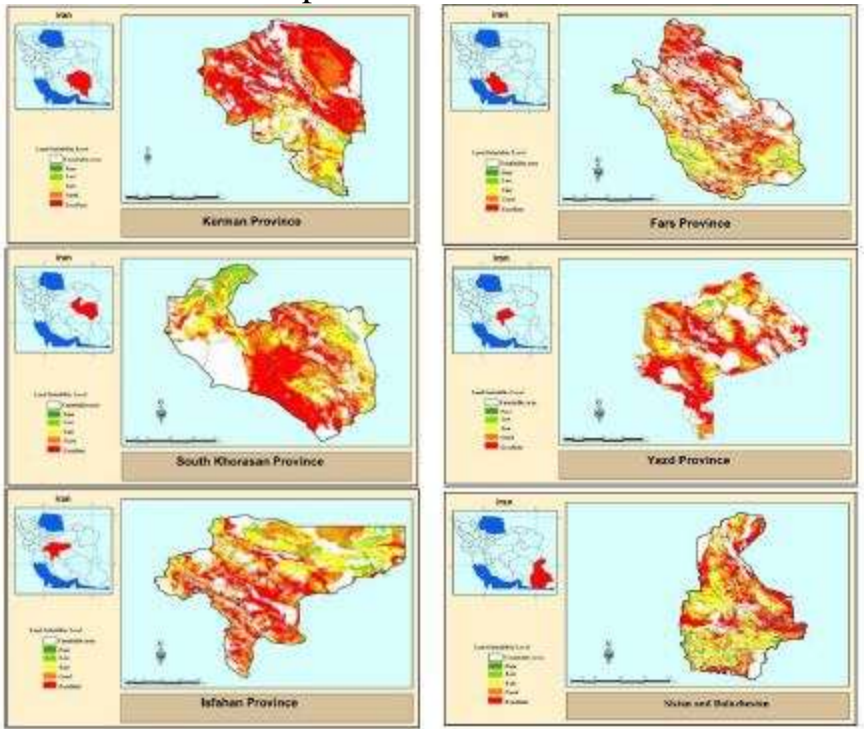

Figure 4. Closer view of the geographical location and classification in the most suitable provinces

\section{Conclusions}

As a developing country and considering the growth of energy consumption, Iran needs to develop and increase its energy generation capacity. Unavoidably, it should consider a special status for planning and providing energy in its developmental plan. Extensive utilization of fossil energy resources across economic sectors has led to increase of pollutants as well as depletion of these resources. Thus, the inclination for the usage of renewable energy resources should be taken into consideration due to characteristics such as renewability, availability, pollution reduction, and, more importantly, Sustainable development. Application of renewable energies including solar energy can assist Iran in achieving goals including diversification of energy mix, application of local energy resources, reducing environmental impacts, and eventually sustainable development of the energy sector. Because of high initial capital investment to set up solar power plants, 
identification of the best sites for exploitation of solar energy may be the most important step in the development of this industry. This study provides a practical approach, considering technical, environmental, geographical, and economic criteria, to assess and prioritize various regions of Iran for exploiting solar energy using geographical information system (GIS) and fuzzy AHP technique. The results indicated that $14.7 \%$ of the entire lands in Iran have a suitability level of excellent, $17.2 \%$ are in good level, $19.2 \%$ are in fair level, $11.3 \%$ are in low level, and $1.8 \%$ are in poor level with the lowest priority regarding installation of photovoltaic. Moreover, provinces of Kerman, Yazd, Fars, Sisitan and Baluchestan, Khorasan and Isfahan have the greatest Suitability for the exploitation of solar energy. In order to relate the investigations to real life situations, we consider climatic, executive, technical, and technological limitations in land Suitability modeling in our analyses. For example, due to entrance of dust systems in west and south regions of Iran over the past few years, the factor of the annual average of dusty days has been taken into consideration as one of the influential factors. Regarding the issues of development of solar industry, considering the different limitations ahead of the government, the results of this study can be of interest to the energy planners because of the accuracy of investigations and the obtained results. In addition to the central government and national organizations, the results of this research can assist the relevant authorities and planners at the level of each province together with the investors over the energy area for planning and developing this industry. However, government's aids to provide promotional tools like subsidies, guaranteed purchase contracts and providing the economic situation for private part venture will encourage investors inside and outside the country to invest in solar energy development projects.

\section{v. References}

1. Land Suitability Analysis for Solar Farms Exploitation Using GIS and Fuzzy Analytic Hierarchy Process (FAHP) - A Case Study of Iran

2. Shirazi and Seyed Hassan Ghodsipour Industrial Engineering Department, Amirkabir University of Technology, 424 Hafez Ave, Tehran15916-34311,Iran;

3. Environment Islamic Republic of Iran. Available online: http://www.doe.ir/

4. Renewable Energy Organization Of IRAN: http://www.suna.org.ir/

5. United Nations. Adoption of the Paris Agreement. In Proceedings of the Conference of the Parties,Twenty-First Session, Paris, France, 30 November-11 December 2015. 